\title{
CONSERVATION OF CULTURAL HERITAGE IN MINORITY ETHNIC REGIONS IN NORTHWESTERN CHINA-AN EXPLORATION AT KUQA, XINJIANG
}

\author{
WU Nan ${ }^{\mathrm{a}}$ ZHANG Xiaochuan ${ }^{\mathrm{a}}$ \\ aTHID, F3\&4, Building1, No.41 Shangdi West Road, Haidian District, Beijing, P.R.China - (wunan, zhangxiaochuan)@thid.cn
}

KEY WORDS: Historic city, Renovation, Minority Ethnic Region, Urban Fabric

\begin{abstract}
:
Kuqa, Xinjiang, is located at northwestern inland china. Traditionally a bridge between eastern and western civilizations, Kuqa had a history of cultural fusion and was left with abundant cultural heritage. As population increase, economic growth and social changes occurred, spontaneous renovation of the old city was affected, in which street fabric and scenes underwent damages. The paper demonstrates attempts made in various projects to achieve conservation of cultural heritage in agreement with economic development and improvement of living condition. The lessons learnt in these projects will be of value to development of other historic cities, especially in minority ethnic regions in China.
\end{abstract}

\section{BACKGROUND INFORMATION OF KUQA}

Kuqa County, called Qiuci (龟兹) by ancient Chinese people, is located in the southern half of the Xinjiang Uygur Autonomous Region of China, which, geographically, is part of Central Asia. The population of Kuqa consists of several ethic groups, yet is predominated by Uighurs.

The urban area of Kuqa County consists of three sections, namely, the old city, the new city, and the eastern district. The old city, traditionally inhabited by Uighurs, occupies the westernmost end of the urban area. The new city, in comparison, is the county-wide modern cultural, political and commercial center. The eastern district is an area devoted to modern industry.

The complex historical accumulation and multicultural background makes Kuqa a worldly unique place. The old city preserves a very traditional urban spatial texture and architectural style that resembles history. Not only is the area historically integral and authentic, but also is the traditional ethnic preserved, which has distinctive regional and ethnic characteristics and is still vibrantly alive. The 2006 County Master Plan establishes Kuqa as a Regional Historic City. At 2012, Kuqa is listed as a National Historic City.

In recent years, industrial economy in Kuqa is ever on the rise, with petro-chemical industry replacing agriculture and animal husbandry as the major driving force of economic growth. Leaps are achieved in the lead of big industrial projects supported by national investment. Tourism is rising too, as "Qiuci Cultural Tourist Spot" is ranked among "Xinjiang's Top Ten Tourist Attractions". Pressures of urban construction are rising with economic growth, which poses serious challenges to the conservation of urban historical and cultural heritage.

Adding to top-down pressures of urban rebuilding, disordered addition and alteration of buildings on the part of local residents is motivated by deterioration of living conditions and population growth, threatening the existence of traditional urban fabrics. Therefore, protection of historic blocks is crucial and difficult as well.

\section{COMPILATION OF CONSERVATION PLANS FOR KUQA}

At 2008, Our team was invited to compile the Cultural Relics Conservation Plan and the Historic City Conservation Plan for Kuqa County, and provide assistance in its application for the nomination as a National Historic City. At 2010, the compilation work was completed, application material submitted, with the rest of conservation tasks carried on by staff of the relevant local government agencies.

The plans stressed the effective linking between foundational data and planning execution. Balance between the "city" and the "areas", between spatial entities and cultural vigor was seen as crucial in the plans. Moreover, the plans urged that urban functions, infrastructures, and environments should be improved, as should social justice and cultural diversity be promoted along the execution.

Many difficulties were overcome during the planning process, including inadequate foundational research, lack of relevant historical and architectural data, weak awareness of conservation among the public. These all add to the workload of the planners. However, the work won the friendships between planners and local government officials in charge of cultural relics and town planning, which in turn helped the planners to maintain an on-going service.

\section{URBAN PROBLEMS AFTER KUQA BECAME A NATIONAL HISTORIC CITY}

The old city had more than thirty thousand native residents, with Uighurs comprising the majority. Other ethnic groups are Huis and Han Chinese. According to prior census data, most families had lived in the old city for more than five generations, and construction of many residential buildings dated back to $19^{\text {th }}$ century. More than 200 years of occupancy witnesses the accumulation of both cultural beauty and practical urban problems. These problems were not recognized before planning. 


\subsection{Shortage of Residential Land in Response to Population Growth}

There are two aspects to the problem of land shortage. The first is local culture. Families grow over time, but in alignment with traditional customs, most residents choose to stay rather than leave the community.

The other aspect is policy. Most families had more than two children, which were allowed by national policy and laws for minority ethnic groups, therefore families grow in faster pace than those of Han people.

The result is ever more cramped residential space for families that hardly satisfies the needs of modern lifestyle. When children grow into adults and form independent families, the usual practice was to split the former family courtyard into two halves with a partitioning wall. Former courtyards were either replaced by rooms or divided into smaller courtyards.

\subsection{Low-Income Families Unable To Support Renovation of Residential Buildings}

More than half of native inhabitants have little income and lives on social security alone, thus cannot afford to repair common damages to their buildings. Buildings decay over time to the extent of breeding potential physical dangers. Thus, the successive and spontaneous mode of renovation, though commonly advocated in conservation of historic blocks, is scarcely feasible in this case.

Most residents earned a little extra income by small trades within the community. If relocated somewhere else, they would lose the original clients and market. The problem was not so much getting used to a new environment, compared to losing the only way of earning a living.

\subsection{Bad Living Conditions}

Most families were not connected to public water systems. Almost all families had no sewers for everyday waste water, which they drained directly to the alleys despite pollution of public space.

Central heating and natural gas lines were lacking as well. Coal burners were used for heating, causing smoke to shroud the blocks in winter, heavily worsening the air quality.

Most houses had wooden structures and lot of wooden components. However, fire trucks were unable to access the narrow lanes between buildings, therefore fire dangers were ever threatening.

The historic blocks had only a few scattered public toilets and dump sites, which cannot form a complete sanitation system.

\subsection{Amenities Still Wanting}

The historic blocks had almost no land for commercial, institutional and green uses. No cultural activities centers and health service stations exist at the community level. Open space for relaxation, exercise and leisure also wait to be built.

\subsection{Damage of Traditional Architectural Fabrics}

Three kinds of damages were prevalent in the area. There were gradual corrosions due to lack of maintenance. And there were also tearing down of old buildings to make place for new ones due to residential needs. Some damages even happened when people can afford to "refurbish" their houses, destroying traditional architectural fabrics and styles.

\subsection{Impact of Terrorism on Tourism}

Tourism is heavily impacted by recent terrorist attacks not only at Kuqa but throughout the entire Xinjiang. Housing prices fall drastically and original facilities provided for tourism were very rarely, if ever, used by visitors.

\section{EXPLORATION IN CONSERVATION: FOUR PROJECTS}

\subsection{Project 1: The Sukuwuke Community_Block 1}

4.1.1 Origination: At 2011, the Planning Bureau of Kuqa informed us that new government officials intended to demolish a preserved historic block, and build a modern, 6storey residential building block in its place. The planners at Beijing were urged to work out an alternative plan that attended to the conservation needs. Fortunately, the original plan was never executed. After the formal acceptance as National Historic City, government officials gave up the original plan to build modern 6-storey buildings, and requested us to work out our conservation plan in detail.

Though we did not agree with the original plan to demolish the block, we were fully aware of how such an intention was motivated from many sides. Firstly, a higher government official once saw the dilapidated scene when visiting the old city of Kuqa, and ordered the local government to renovate the area. Secondly, ensuring safe living conditions for people had ever been a long-term policy, while many residential buildings in the old city were indeed in poor conditions. Thirdly, such projects were qualified for funds from Ningbo, the appointed aiding city, thus relieving financial pressure for the Kuqa County.

4.1.2 Background Information: The renovation section is situated in the north of the. The site is 1100 meters long, 370 meters wide, and an area of 7.54 hectares.

Land use within the community is almost entirely residential. The community contains a middle school, two mosques. Land use around the community is mainly residential. To the southwest of the community situates the oldest Mosque citywide_— Kuqa Grand Mosque, in opposition to the QingDynasty Junior City. The community is the first residential area to appear in view on a car drive from the airport to the city of Kuqa.

Residential use, institutional use, public greens, and road use take up $78 \%, 0.5 \%, 0 \%$ and $20 \%$ of total land use respectively, which means that the area is filled by residential and road land, with almost nothing left for institutional use and public greens.

There is currently one building registered for protection. Various forms of damages occur to other existing buildings such as natural corrosion, illegal alterations or complete abandonment.

\subsubsection{Design Conditions and User Requirements}


- Roads: Roads within the community are either dirt roads in small alleys or main roads paved with bricks. The roads had varying widths due to spontaneous development that formed the community, and the roads were further narrowed by roadside poplar or mulberry plantations. This poses serious difficulty to municipal pipeline laying.

- Land Use: Residential land constitutes a large proportion, while there is almost no land for commercial, institutional and green uses. Public service amenities are lacking. There are no cultural activities centers and health service stations at the community level. Open space for relaxation, exercise and leisure also wait to be built.

- Municipal infrastructure and amenities, such as water systems, central heating and public toilets are lacking on the whole.

- House-splitting Requirements: The limited area has to fulfill the house-splitting and relocation needs. Housesplitting demands were put forward by more than half of the families, 30\% among who required that their house split in more than three parts. Some of the courtyards were decided to be demolished, in order that the whole area could accommodate 303 families.

4.1.4 Concessions and Modifications of Upper-level Conservation Plan: Demands put forward at the initial stage by upper-level plans on floor area per capita and relocation cannot be totally met.

Local residents - the original demand to provide housing for 336 families is lowered to 303 families according to census, while area per capita remains $28 \mathrm{~m}^{2}$, which is in accordance with building codes.

Local government-Policy of total local relocation is changed to encouragement of moving out.

Designer-Preserve the protected buildings in the blocks, while other yards depend on residents' own will. Requirements in the conservation plan were not strictly adhered to.

Population growth and addition of public facilities would necessarily raise the building intensity. In order that an original fabric is preserved, the community is divided into different parts for construction control. A small part is planned for high building intensity. The original intention for spatial allocation, namely one courtyard per family, can hardly be insisted throughout the area. In this case, collective housing and shared courtyards are inevitable.

Restriction on building height is altered on account of visual and spatial considerations. At the time of planning, reconstruction of Tianshan Road, which is north of the site, had recently completed, which involved a 3-meter raise of the road plane. Only the upper story of residential buildings could then emerge from the road plane, hindering thorough presentation of the characteristic architectural style on facades. Therefore the 7-meter building height limit of the conservation plan is transgressed to allow for taller buildings that had better exterior visual quality and larger floor area, which provided housing for all relocation residents.

\subsubsection{Planning and Design}

- Zoning: The whole area is divided according to existing roads into zones A-K, 11 in total.

Zone A and B are adjusted to controlled construction area. All other zones follow the original courtyard fabric strictly in renovation. This is because Zone A and B are closer to the Tianshan Road, which is 3 meters higher than the surrounding ground surface. This adjustment would enlarge total floor area, and form more prominent building façades facing Tianshan road. Nevertheless, those yards near the mosques remain one-story in height.

Collective housing units are positioned within part of zone $\mathrm{G}$ and $\mathrm{H}$. They are composed of small yards that enclosed by boundaries of old courtyards. They adhere strictly to the general 7-meter building height limit and 4.5-meter height limit near the mosques and roads.

- Overall Structure and Nodes: The whole community is divided into three residential sections, two serving sections and six controlling nodes.

Two of the three residential sections are situated in the north, the other in the south.

The two serving sections are the one composed of a mosque, a kindergarten, a funeral parlor and a small square, and the other composed of a clinic and a street office.

The six controlling nodes are the three serving nodes, two landscape nodes and one conservation-exhibition node respectively.

Cultural activities node: The narrow area to the south of Wurongbage Mosque is adjusted to a community cultural activities center, which includes a public exhibition hall, a kindergarten, in order to meet fundamental education and entertainment needs.

Tourist node: Taking into consideration the inevitable development of tourism, a tourist node is placed at the crossroad of the Tianshan Road, the area's main traffic route to the outside, and the Tenth Alley of Pahetabazha Street, the main automobile road.

Community service node: The community service node is formed by a new neighborhood committee office built at the area west of the community clinic.

Conservation-exhibition node: The only protected building locates at the southwestern corner of the area, near the old site of Sukuwuke Gate. It is typical of Kuqa Han Chinese style of residential buildings. The surrounding space is cleared to give prominence to the building.

- Laying of Municipal Pipelines: The upper level conservation plan requires that boundaries of existing roads and canals should remain the same, and red lines of roads should overlap with those of buildings.

Specific spatial means are used to ensure that the feel of enclosure does not disappear because of widening of roads. The narrowest of existing lanes is 2.8 meters wide, while the least road width for proper laying of municipal pipelines is 4 meters. Thus, pergolas, seats and vegetation are placed at both sides of courtyard walls to create more enclosing surfaces, thus retain the geometrical proportion between 
roads and fixed structures at their sides.

- Street space: 17 different elevation patterns for roadside building facades are carefully designed to ensure traditional Kuqa street scenes, which are defined at elemental level such as yard gates, doors, walls, overhangs, corridors, arches and meter room doors.

- Buildings: the protected building had a separate renovation design. Four new buildings are designed: the tourist service center, community clinic, kindergarten and funeral parlor.
Among the residential buildings, forms of independent yards are adapted from variations of the traditional prototype "Mehmanhana" to serve modern living functions. Collective housing yards are also designed to meet relocation needs. Prices of collective housing are lower compared to independent yards thanks to national aids for small apartments, and are thus more suitable for low-income residents.

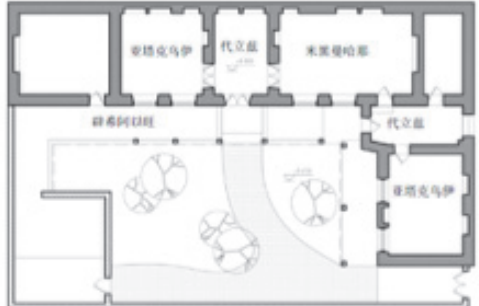

A Mehmanhana House Plan

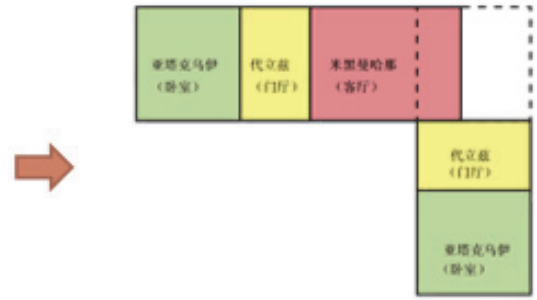

Composition of a Mehmanhana House

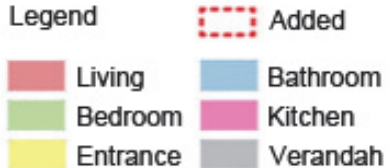

Entrance Verandah

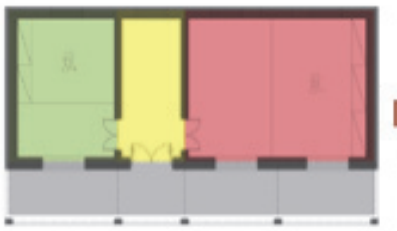

Traditional

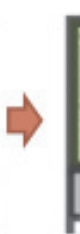

Updated

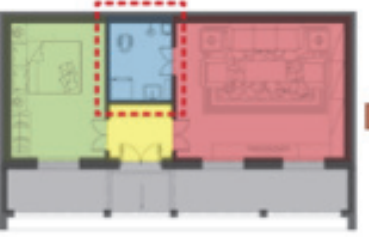

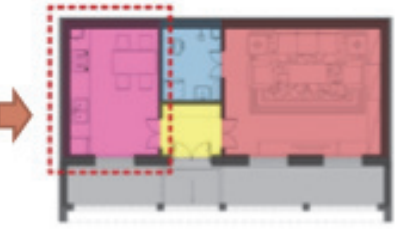

Variation I

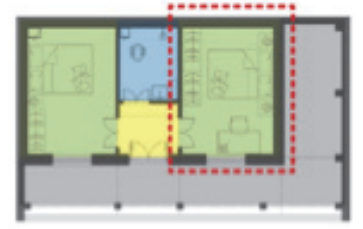

Variation II

\subsection{Project 2: The Sukuwuke Community: Block 2}

4.2.1 Origination: Block 1 and 2 belong to one community originally. However, due to funding constraints, only block 1 was renovated at first. It cost 100 million Yuan, which was considered expensive by the local government. In the renovation of block 1 , many building components, such as windows and doors, were custom-made wooden ones, instead of cheaper machine-made ones made of aluminium alloy. These components cannot be simply bought in batches from the market. Introduction of municipal pipelines were also costly.

The mode could not be duplicated at block 2. The local government and residents all hoped to spend the least to improve basic living conditions and landscape.

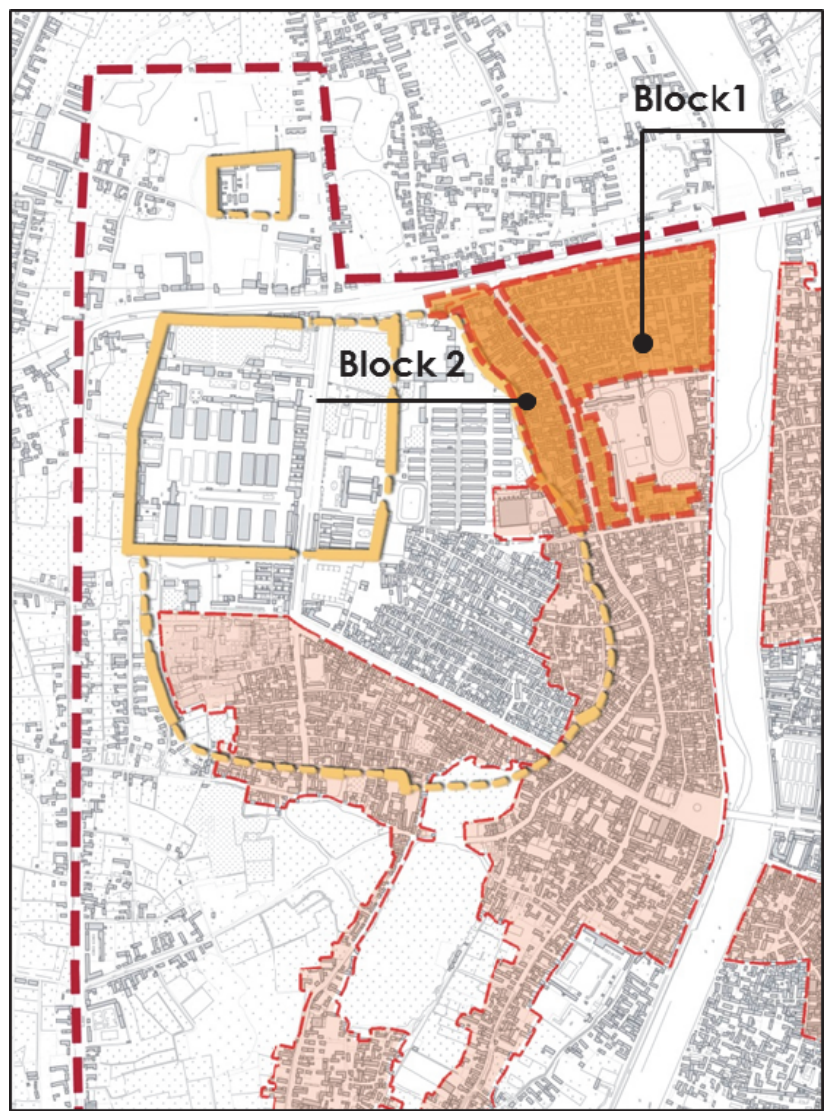




\subsubsection{Background Information}

- Residents: Almost $1 / 3$ of all residents were unemployed. Nearly $1 / 3$ were self-employed. $23 \%$ percent of them were retired. Full-employment and part-time employment were low in percentage.

Economic status of residents was better, compared to block 1, yet residents were equally reluctant to move out, and lacked the will to renovate their buildings.

- Buildings: The yards were rather small, and had lots of additions compared with the situation at 2008. Most buildings had brick structures, with a few wooden ones. Most buildings were in fairly good conditions. Floor area ratios of yards centered around 0.9 , which was quite reasonable rate. Main alleys were 2 to 4 meters wide, while the favorable widths were 4 to 5 meters, taking the laying of pipelines of water, drainage and natural gas. No new public facilities needed to be built, since those in block 1 would be enough.

No major alteration to existing buildings was needed, except necessary demolition at fire safety bottlenecks and exhibition spots of city walls.

Meanwhile, $60 \%$ of roadside buildings were insufficient for proper street scenes. They had white tiles and iron scaffolding, with additions of color plates that stretched to roads.

- Renovation Plan: Taking various factors into account, the plan had two emphases. Firstly, municipal pipelines should enter every family. Secondly, roadside façades were to be restored in better order. The good news was that most existing buildings were brick ones and could be torn down. Also, there were green space reserved by upper-level plans which made room for buildings. After discussion with local residents, we came up with three options:

Option 1: Yards west of the north-south road are reduced in width by 3 meters. Yards at each side of the two east-west roads recede from the roads by 1.5 meters. Five yards are removed (including four houses and one warehouse). Yards owned by 48 families are reduced, and yards owned by 9 families have to be expropriated.

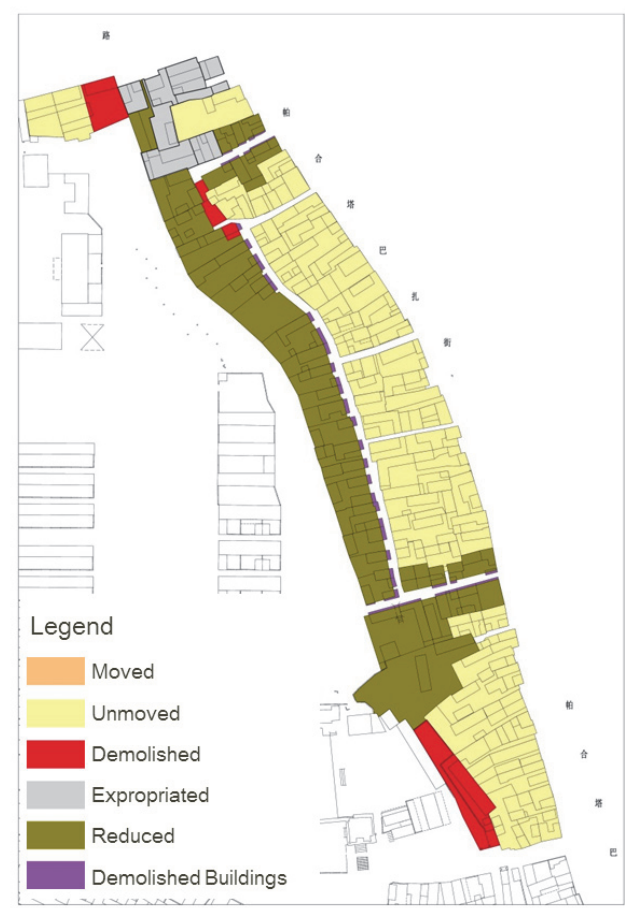

Option 2: Yards west of the north-south road are reduced in width by 1.5 meters. Yards at each side of the two east-west roads recede from the roads by 1 meter. Five yards are removed (including four houses and one warehouse). Yards owned by 64 families are reduced, and yards owned by 9 families have to be expropriated.

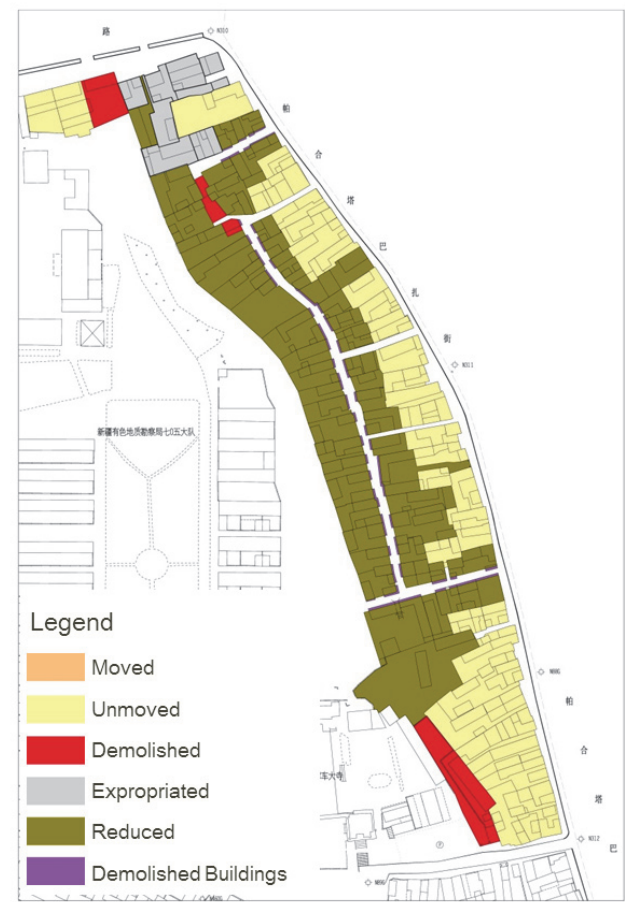

Option 3: Yards west of the north-south road are translated by 3 meters. Yards at each side of the two east-west roads recede from the roads by 1.5 meters. Five yards are removed (including four houses and one warehouse). Yards owned by 
27 families had to be translated. Yards owned by 21 families had to be reduced. Yards owned by 9 families had to be expropriated.

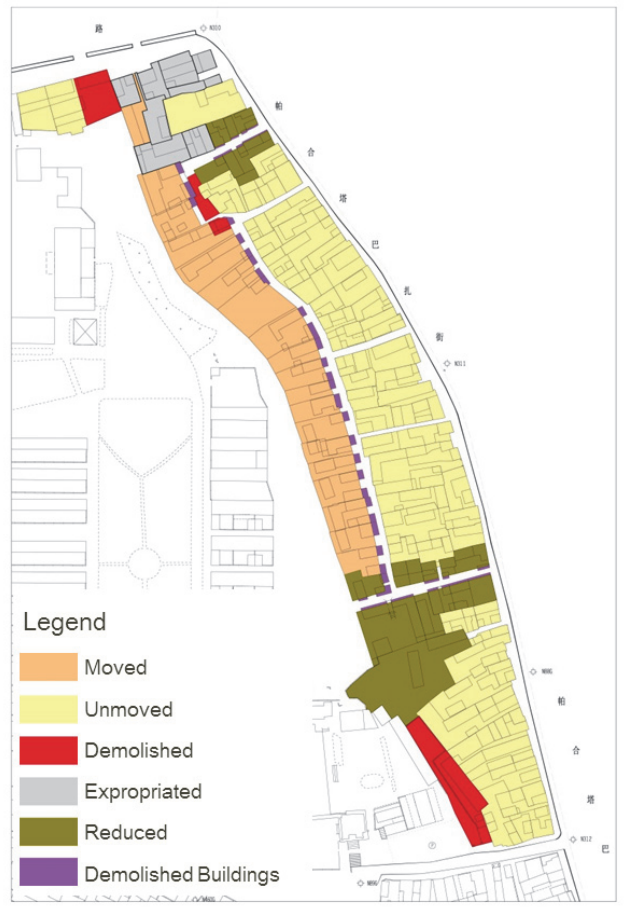

There were 9 yards that had been expropriated whose buildings almost collapsed completely. The plan was to distribute the yards to ten families as relocation and commercial housing. However the project is at a standstill now, since the government is concentrating on more urgent

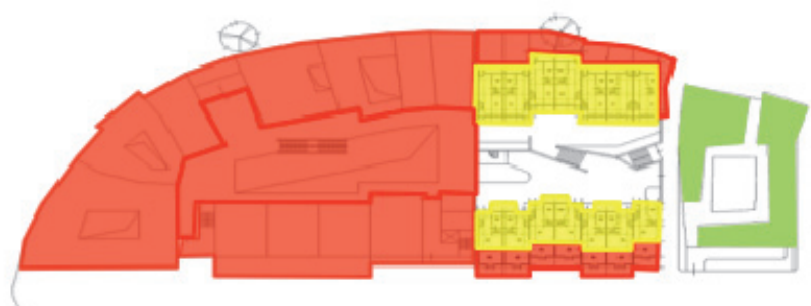

In plans and elevations, the original architectural fabric serve as a guide for symbolic expressions.

At both sides of the protected building, enough room is left for fire channels.

The residential section is divided into eastern and western halves, both centering a courtyard, in which trees that are seldom seen in Xinjiang are preserved.

Large commercial spaces are placed in the western part of the site. Small shops are placed along the side facing the street. Business spaces are arranged underground.

In terms of construction costs, our new design is more economic than the former one. tasks of social stability maintenance.

\subsection{Project 3: The Sakesake Project}

4.3.1 Origination: The site is located in the center of Sakesake, a historic block. To the north of the site lies an important commercial street. To the south of the site lies an important modern urban street. The renovation task was initially entrusted to a local design company. Demolition of front part of the area was already finished. The construction came to a halt when large quantities of Tang-dynasty coins were excavated when digging the foundation. Only then did the team know that the area had been demolished except the building registered for protection, and all other buildings to be constructed was designed from scratch.

4.3.2 General Information: The site is located in the north of Sakesake block, near Renmin Road. In the middle of this strip of land lies a protected building. The site covers $6420 \mathrm{~m}^{2}$, the total built area being $10800 \mathrm{~m}^{2}$.

This site is different from the Sukuwuke Community in that it is not a purely residential aream, but viewed highly in economic value by local government officials. We set the objective of planning as balance between development and conservation, based on survey data and estimation of construction cost.

4.3.3 Planning and Design: For such an important area in a historic block, we hoped to preserve the original urban fabric, thus limited the height to no more than two stories. Relocation ratio is set at $1: 1$. Commercial and business areas are added, and requirements on floor areas in the former design are retained.

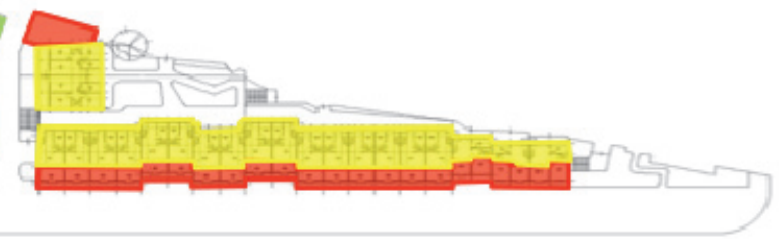

4.3.4 Current Status: Construction has nearly finished, which present a good overall condition, except for some railing components that needed reinforcement. Courtyard spaces in the residential area are comfortable. Residential flows and commercial flows are separated and do not interfere with each other.

\section{SOURCES OF DIFFICLUTY IN CONSERVATION}

\subsection{Population Growth}

The major ethic group in the old city of Kuqa is the Uighurs, who enjoyed a more liberal child-bearing policy compared to Han Chinese and Hui people. Therefore, population grows faster than that of mainland Chinese cities, resulting in ever scarce residential and infrastructure land use. Existing buildings suffer constant pressure for alteration and addition, and practical considerations naturally come before other values for local residents. 


\subsection{Local Customs}

The local custom is for children to use separate spaces from their parents when they form independent families, while remaining in the community. So the usual practice is to split the original yards and units in order that the new families enjoy an independent part. Whole buildings may be cut in half or more portions by new yard walls, losing original spatial pattern and scenes.

Reluctance of moving out is another cause of increase in population density. Community members do not want to move out of their familiar blocks. The government has made attempts to locate some residents elsewhere, but they eventually returned to the old city, for they are deprived of means of living when having moved to a new place, while in the old city they can still rely on running small stands.

\subsection{Lack of Awareness of the Cultural Value of Buildings}

Local residents remain largely unaware of the historic and aesthetic value of their houses. The most obvious manifestation is their following the inextricable patterns of West-Asian Islamic architectural style seen in Kashgar, ignoring the elegant, culturally rich and unique style that blend Chinese, Uighur and Islamic elements.

\subsection{Lack of Conservation Awareness}

Both the local government and residents show lack of conservation awareness. Old buildings were torn down and replaced by new buildings that conflict with old styles, which locals were not fully aware. The local government may curtail conservation funds, leaving some of the buildings that should enjoy registered protection in an absence of maintenance. More severe damage may happen in urban development projects initiated by the government. An entire historic block may be demolished and replaced with brandnew buildings without appropriate considerations for conservation.

\section{CONCLUSIONS}

Cultural conservation in Chinese minority ethnic regions has both unique value and difficulty and facing them is essential in both design and preservation actions.

The unique cultural value of these regions lies in its diverse cultural elements that often reveal a long and distinctive multi-cultural history. These regions are relatively distanced from traditional commercial and economic centers, thus may preserve more ancient and local art forms and lifestyle, and exhibit influences from multiple sources.

The difficulty in conservation derives largely from the same factors that made the region culturally valuable. Many regions suffer from underdevelopment precisely because of the distance from economic and cultural centers that helped preserved the local culture. Therefore, demands in economic development, calls for improvements in living conditions, and insistence on traditional social customs on the side of the local residents and government should all be taken into consideration in order that conservation efforts become more feasible and effective.

The more development becomes inevitable, the more culturally responsible should designers and conservation professionals behave. Design actions are part of attempts in conservation, with the role of design actions in the conservation being more to restore and reuse than to replace and remove. It is also the designers' task to extract essential forms that are in alignment with the lifestyle of residents inherent in the physical configuration of cultural heritage, and apply them in new projects. It is often the case that in projects of alteration, parts of the land originally for residential use should be shifted to commercial or infrastructural use, and it is the architect's and urban designer's job to transplant to new projects the forms, styles, and scenes that are manifested in traditional residential buildings and building blocks.

Nevertheless, the authenticity of existing fabric depends on local administration as well as spontaneous protection by the residents in everyday life. Heritage documentation is of fundamental importance in both preservation and design actions in that any new project that attends to the cultural heritage require that designers, clients and users have adequate understanding of the relevant cultural tradition, which can only be discovered if good documentation is already in place. 